\title{
Efisiensi Penurunan Kandungan Uranium dalam Limbah Cair Pengolahan Monasit Menggunakan Resin Penukar Kation Tulsion T-40 Na
}

\section{Efficiency of Uranium Content Reduction on Waste-water from Monazite Processing Using Tulsion T-40 Na Cation Exchanger Resin}

\author{
Inda Robayani Walayudara ${ }^{1}$, Roza Indra Laksmana ${ }^{1}$, Dany Poltak Marisi ${ }^{1}$, Septyana Nur Amalia ${ }^{2}$ \\ ${ }^{1}$ Pusat Teknologi Bahan Galian Nuklir-BATAN, \\ Jl. Lebak Bulus Raya No.09, Pasar Jumat, Jakarta, Indonesia, 12440 \\ ${ }^{2}$ Program Vokasi Analis Kimia, Program Studi Analis Kimia-IPB \\ Jl. Raya Pajajaran, Kampus IPB Baranangsiang, Bogor, Indonesia, 16144 \\ *Email: inda.robayani@batan.go.id
}

Naskah diterima: 31 Oktober 2019, direvisi: 20 November 2019, disetujui: 30 November 2019

DOI: $10.17146 /$ eksplorium.2019.40.2.5627

\begin{abstract}
ABSTRAK
Limbah cair merupakan salah satu hasil dari proses produksi yang mengandung beberapa campuran atau senyawa kimia yang berbahaya. Salah satunya adalah limbah cair dari proses pengolahan monasit yang mengandung unsur radioaktif, yaitu uranium (U). Limbah cair yang mengandung unsur radioaktif, terutama uranium, menjadi bahan berbahaya apabila terlepas ke lingkungan karena kanndunga nuklida aktif nya yang dapat mempengaruhi kesehatan lingkungan dan masyarakat. Oleh karena itu, perlu dilakukan pengolahan limbah cair dari pengolahan monasit. Metode yang digunakan adalah proses pertukaran ion dengan resin kation yaitu Tulsion T-40 Na yang dapat menurunkan kandungan uranium dan kandungan kation lainnya pada limbah cair pada konsetrasi rendah. Pertukaran ion dilakukan melalui proses pengadukan dengan variasi bobot resin dan waktu kontak. Pengukuran kandungan uranium dilakukan dengan Spektrofotometer UV-Vis, sedangkan pengukuran $\mathrm{pH}$ dan nilai TDS pada limbah cair dilakukan untuk mengetahui karakteristik limbah. Hasil penelitian menunjukkan kondisi optimum proses pertukaran ion pada bobot resin $1,5 \mathrm{~g}$ dengan waktu kontak selama 300 menit menghasilkan penurunan kadar uranium sebesar $83,40 \%$.
\end{abstract}

Kata kunci:limbah cair, monasit, penukar kation, uranium, resin Tulsion T-40 Na

\begin{abstract}
Waste-water is one of the production process that contains several dangerous mixtures or chemical compositions. One of them is waste-water from monazite processing which is containing radioactive element like uranium $(U)$. Waste-water with radioactive content, mainly uranium, became a hazardeous content if it is released to the environment because of its active nuclide content that effect the environment and community health. Therefore, it is necessary to treat waste-water from monasite processing. The method used is ion exchange process with a cation resin, namely Tulsion T-40 Na, which can reduce uranium content and other cations in waste-water at low concentration. Ion exchanging is conducted through stirring process with resin weight and contact time variations. Measurements on uranium content are carried out using the UV-Vis Spectrophotometer, while measurements on $\mathrm{pH}$ and TDS values in waste-water are conducted to determine the characteristics of the waste. The results showed that optimum condition of the ion exchange process at $1.5 \mathrm{~g}$ resin weight with 300 minutes contact time is resulting a reduction on uranium content as much as $83.40 \%$.
\end{abstract}

Keywords: waste-water, monazite, ion exchange, uranium, Tulsion T-40 Na cation resin 


\section{PENDAHULUAN}

Monasit ((Ce,La,Y,Th) $\left.\mathrm{PO}_{4}\right) \quad$ adalah senyawa fosfat yang mengandung Rare Earth Elements (REE) umumnya lantanum (La), neodimium $(\mathrm{Nd})$ dan serium $(\mathrm{Ce})$ [1]. Data hasil analisis dari penambangan timah di Pulau Bangka menunjukkan bahwa monasit tersebut mengandung $\mathrm{RE}_{2} \mathrm{O}_{3} \quad 58,97 \%$, uranium (U) 0,298\%, torium (Th) $4,147 \%$ dan fosfat $\left(\mathrm{PO}_{4}\right) 23,712 \%$ [2].

Unsur logam tanah jarang (REE) memiliki kandungan tertinggi di dalam monasit yang merupakan material baru untuk dapat dimanfaatkan serta dikembangkan di industri. Unsur logam tanah jarang pada masa yang akan datang akan semakin strategis untuk bahan baku, sehingga perlu diupayakan untuk dapat dikembangkan secara berkelanjutan. Namun, monasit memiliki kandungan unsur radioaktif yang memancarkan radiasi berupa torium dan uranium yang dapat berbahaya bagi lingkungan.

Monasit dapat diolah untuk dipisahkan dari pengotornya melalui metode kimiawi yang akan menghasilkan garam unsur $\mathrm{U}, \mathrm{Th}$, $\mathrm{RE}$, dan fosfat [3]. Unsur-unsur tersebut dapat dipisahkan dari monasit secara individu dengan cara proses pemisahan dan pemurnian secara bertahap [4]. Proses pemisahan monasit dapat dilakukan melalui beberapa metode, antara lain: metode basa, metode asam, metode kloronisasi, dan metode reduksi suhu tinggi. Proses pemisahan pada umumnya dilakukan dengan menggunakan metode basa dan metode asam. Sementara itu, proses pemurnian umumnya menggunakan metode pengendapan dan ekstraksi pelarut [2].

Proses pemisahan menggunakan metode basa dilakukan dengan larutan $\mathrm{NaOH}$. Terdiri dari beberapa tahap yaitu dekomposisi, filtrasi, pelarutan, pengendapan $\mathrm{U}(\mathrm{Th}) \mathrm{OH}$, dan pengendapan total (RE) $\mathrm{OH}_{3}$. Hasil yang diperoleh berupa endapan $\mathrm{RE}(\mathrm{OH})$ [3]. Proses pemisahan dengan metode basa menghasilkan limbah cair yang bersifat basa yaitu filtrat hasil pengendapan. Limbah cair tersebut mengandung unsur radioaktif karena masih adanya kandungan uranium dan torium di dalamnya. Selain itu, terdapat pengotor berupa fosfat $(\mathrm{P})$, kalsium $(\mathrm{Ca})$, aluminium (Al), besi (Fe), mangan ( $\mathrm{Mn})$, timah $(\mathrm{Sn})$, dan silikon ( $\mathrm{Si})$ di dalamnya yang nantinya dapat dihilangkan [5].

Limbah cair yang dihasilkan dari hasil proses pemisahan unsur harus dilakukan pretreatment (pengolahan) sebelum dibuang ke lingkungan. Kandungan radioaktif yang terdapat di dalam limbah cair tersebut dapat memberikan dampak buruk kepada lingkungan dan masyarakat apabila terlepas ke lingkungan dalam konsentrasi yang tinggi.

Menurut Perka BAPETEN No.16 Tahun 2012 nilai ambang batas dari Tingkat Klierens untuk radionuklida alam, termasuk di dalamnya adalah limbah radioaktif berupa kandungan uranium adalah sebesar 0,81 ppm [6]. Apabila melebihi dari nilai ambang batas tersebut, maka akan menimbulkan risiko yang berdampak buruk bagi lingkungan dan masyarakat.

Efek radiasi dapat menimbulkan risiko yang memicu efek stokastik (sel hidup abnormal), yaitu kanker atau efek deteriministik (disfungsi sel organ) yaitu cacat tubuh. Uranium adalah unsur radioaktif lemah yang terjadi secara alami. Tingginya kandungan uranium dalam limbah cair apabila tersebar ke lingkungan dapat meningkatkan risiko kanker dan kerusakan ginjal [7].

Proses pengolahan pada limbah cair dapat dilakukan dengan beberapa metode salah satunya adalah proses pertukaran ion 
menggunakan resin. Metode pertukaran ion ini memiliki keuntungan dapat menurunkan kandungan uranium pada limbah cair yang memiliki konsentrasi rendah.

Resin penukar ion merupakan senyawa hidrokarbon terpolimerisasi yang mengandung ikatan silang (crosslinking) serta gugus-gugus fungsional yang mempunyai ion-ion yang dapat dipertukarkan. Pertukaran ion merupakan salah satu metode pemisahan ion dalam larutan melalui proses pertukaran ion yang terikat pada polimer dengan ion dalam larutan. Proses pertukarannya berlangsung tanpa menyebabkan perubahan sifat fisik dan strukturnya [8].

Jenis resin terbagi mejadi dua yaitu resin penukar kation dan resin penukar anion. Resin yang digunakan untuk menurunkan kandungan uranium dalam limbah cair adalah resin penukar kation, yaitu Tulsion T-40 Na. Resin Tulsion T-40 Na merupakan tipe resin asam kuat dan memiliki gugus fungsi $\mathrm{Na}^{+}$ sebagai gugus penukar. Selain itu resin ini memiliki ukuran 0,3 sampai 1,2 mm dengan matriks kopolimer polistirena [9].

Gugus fungsi $\mathrm{Na}^{+}$tersebut akan terlepas dari resin dan ditukar dengan $\mathrm{U}^{2+}$ pada limbah cair yang kemudian akan terikat pada resin, sedangkan untuk gugus fungsi $\mathrm{Na}^{+}$akan ikut pada effluent dari proses pertukaran ion. Ukuran resin juga menentukan jumlah kation yang akan ditukar tergantung pada kapasitas resin tersebut.

Penelitian yang telah dilakukan adalah pengolahan uranium cair dengan penggunaan variasi perbandingan bobot resin campuran (kation dan anion). Hasilnya menunjukan bahwa penyerapan uranium yang baik terjadi pada resin kation dibandingkan dengan anion. Karena uranium memiliki muatan positif, pertukaran terjadi secara maksimal pada resin kation sedangkan untuk resin anion hanya menyerap di bagian permukaannya saja [10].
Oleh karena itu, penelitian dilakukan menggunakan resin penukar kation yaitu Tulsion T-40 Na dengan memberi perlakuan variasi waktu dan bobot resin. Tujuan dari penelitian ini adalah mengetahui efisiensi penurunan kandungan uranium menggunakan resin Tulsion $\mathrm{T}-40 \mathrm{Na}$ dari limbah pengolahan monasit.

\section{TATA KERJA}

Bahan yang digunakan antara lain: limbah cair dari pengolahan monasit di PLUTHO; bromo-2-(2-piridilazo)-5-dietil aminifenol (bromo-PADAP); tri oktil fosfinoksid (TOPO); sikloheksana, asam askorbat; titriplex; natrium fluorida $(\mathrm{NaF})$; asam sulfosalisilat; akuades; natrium hidroksida $(\mathrm{NaOH})$; tri etanol amin; asam perklorat; alkohol; asam nitrat; larutan standar Spex Uranium 10.000 ppm dan resin penukar kation Tulsion $\mathrm{T}-40 \mathrm{Na}$.

Peralatan yang digunakan dalam penelitian ini antara lain: spektrofotometer UV-Vis merk Hitachi seri U-2900; hot plate; magnetic stirer; neraca analitik merk Satorius seri BSA224S-CW; oven furnace merk Ney seri Vulcan D-550; alat gelas; botol sampel plastik; stirer MaxBlend; vortex mixer.

Metode yang digunakan pada penelitian ini adalah metode eksperimen laboratorium dengan proses pertukaran ion menggunakan resin dengan cara pengadukan untuk mengetahui penurunan kandungan uranium yang paling efisien dalam mengolah limbah cair pengolahan monasit. Data yang dikumpulkan merupakan data hasil pengukuran kandungan uranium pada limbah cair pengolahan monasit sebelum dan setelah proses pertukaran ion. Tahapan penelitian yang akan dilakukan terdiri dari karakterisasi limbah cair, penentuan bobot resin optimal dan penentuan waktu kontak resin optimal pada proses pertukaran ion. Data yang 
diperoleh dari hasil penelitian kemudian dilanjutkan dengan analisis data. Penelitian dilakukan di laboratorium analisis pengelolaan limbah di Pusat Teknologi Bahan Galian Nuklir (PTBGN), BATAN pada bulan Februari sampai Mei tahun 2019.

Karakterisasi limbah cair dilakukan dengan melakukan analisis kandungan uranium pada limbah, nilai Total Dissolved Solid (TDS), konduktivitas dan $\mathrm{pH}$ (tingkat keasaman). Limbah cair yang ditampung dalam sebuah drum, kemudian diaduk terlebih dahulu agar homogen sebelum digunakan dalam penelitian. Sebelum melakukan proses pertukaran ion, resin penukar kation dikeringkan dalam oven dengan suhu $80{ }^{\circ} \mathrm{C}$ selama 3 jam, kemudian resin yang telah dioven ditimbang dengan bobot yang berbeda-beda ke dalam labu erlenmeyer. Setelah itu limbah cair pengolahan monasit dimasukan ke dalam labu erlenmeyer yang sama sebanyak $100 \mathrm{ml}$ dan dimasukkan ke dalam magnetic stirer. Variasi bobot resin dalam penelitian antara lain 0,5 gram, 1 gram, 1,5 gram, dan 2 gram.

Proses pertukaran ion, dilakukan menggunakan alat Mix Bland yang akan mengaduk limbah cair dalam erlenmeyer yang dicampur dengan resin menggunakan bantuan magnetic stirrer. Proses pengadukan dilakukan dengan variasi waktu kontak selama 180 menit, 300 menit dan 420 menit. Setelah pertukaran ion melalui pengadukan, selanjutnya limbah cair disaring untuk memisahkan antara resin dan filtratnya. Filtrat hasil penyaringan dicuplik untuk dianalisis kandungan uranium, TDS, konduktivitas, dan $\mathrm{pH}$. Sedangkan efisiensi penurunan uranium dihitung menggunakan rumus:

$\%$ Eff. Penurunan $=\underline{C_{\text {awal }}-C_{\text {akhir }}} \times 100 \%$

$$
C_{\text {awal }}
$$

Ket:

$C_{\text {awal }}=$ Konsentrasi uranium mula-mula

$C_{\text {akhir }}=$ Konsentrasi uranium setelah proses pertukaran ion

\section{HASIL DAN PEMBAHASAN \\ Karakteristik Limbah Cair}

Hasil pengamatan secara visual terhadap limbah cair pada penelitian ini menunjukkan warna kuning keruh. Paramater lainnya seperti pH, TDS dan konsentrasi uranium pada kondisi awal limbah cair hasil pengolahan monasit dapat dilihat pada Tabel 1. Konsentrasi uranium masih berada di bawah nilai ambang batas untuk Tingkat Klierens Radionuklida Alam yaitu sebesar 0,81 ppm [6].

Tabel 1. Karakteristik limbah cair radioaktif awal

\begin{tabular}{cc}
\hline Parameter & Hasil pengukuran \\
\hline Konsentrasi Uranium (ppm) & 0,4046 \\
pH & 11,50 \\
TDS (ppt) & 2,478 \\
Konduktivitas (S/m) & 4,948 \\
\hline
\end{tabular}

Kandungan uranium pada limbah cair hasil pengolahan monasit yang ditangani di PTBGN-BATAN memiliki kosentrasi berkisar $0,4-0,8 \mathrm{ppm}$. Namun, pengolahan tetap dilakukan untuk mengurangi akumulasi dan tidak merusak daya dukung lingkungan saat dibuang ke lingkungan. Bila dilihat dari pH-nya, limbah cair tidak dapat dibuang langsung ke lingkungan karena nilai $\mathrm{pH}$ masih berada jauh di atas baku mutu. Dalam Peraturan Menteri Lingkungan Hidup RI No. 5 Tahun 2014 tentang Baku Mutu Air Limbah, nilai baku mutu pH limbah cair yang diizinkan untuk dapat dibuang ke lingkungan yaitu pada rentang 6,0-9,0 [11].

Penggunaan resin kation tulsion T-40 Na yang digunakan adalah jenis resin dengan 
bentuk natrium yang beroperasi sebagai pelembut dan terbatas dalam mengurangi kandungan uranium. Jenis resin yang terbentuk dari $\mathrm{Na}$ memang sangat tergantung terhadap $\mathrm{pH}$ [12].

\section{Bobot Resin dan Waktu Kontak Optimal pada Proses Pertukaran Ion}

Bobot resin dan waktu kontak optimal pada proses pertukaran ion dapat dilihat dari nilai persentase penurunan kandungan uranium pada limbah cair seperti terlihat pada Gambar 1.

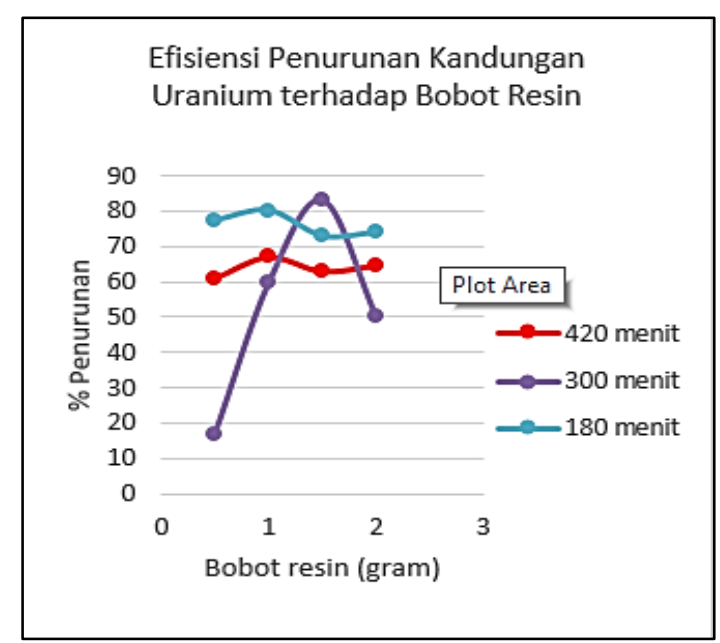

Gambar 1. Hasil Analisis Uranium dalam Penentuan Bobot Resin dan Waktu yang Optimal

Setiap persentase penurunan kandungan uranium berbeda dengan variasi waktu kontak dalam proses pertukaran ion (Gambar 1). Penurunan kandungan uranium yang optimal pada waktu 180 menit didapat pada bobot resin 1 gram dengan efisiensi 80,237\%. Pada waktu kontak 300 menit kondisi optimal didapat pada bobot resin 1,5 gram dengan efisiensi 83,401 \%. Sementara itu, pada waktu kontak 420 menit kondisi optimal didapat pada bobot resin 1 gram dengan efisiensi 67,064\%.

Dari data tersebut terlihat bahwa tingkat penyerapan pada waktu kontak yang berbeda memberikan hasil penyerapan yang berbeda.
Hasil tersebut menunjukan bahwa profil 300 menit memiliki perbedaan dengan kedua profil lainnya. Hal ini disebabkan karena waktu 180 menit sudah cukup memberikan waktu kontak yang optimal dibandingkan dengan yang lain. Daya serap resin akan semakin menurun jika waktu yang digunakan juga semakin lama, karena butiran resin akan semakin halus dan pori-pori permukaan butiran semakin kecil sehingga jika waktu pengadukan yang digunakan semakin lama maka resin akan hancur dan rusak [12].

Efisiensi tertinggi terlihat pada waktu kontak 300 menit dan bobot resin 1,5 gram. Hal ini terjadi karena pada perlakuan tersebut cocok menggunakan jenis resin Tulsion T-40 $\mathrm{Na}$. Persentase penurunan yang menunjukan nilai 83,401 \% memiliki konsentrasi kandungan uranium sebesar 0,06716 ppm. Konsentrasi yang didapatkan menurun dari konsentrasi awal menunjukan bahwa limbah cair yang telah diolah mnggunakan proses pertukaran ion dengan resin Tulsion T-40 Na berjalan secara optimal.

\section{Pengaruh pH terhadap Penurunan Kandungan Uranium}

Pengukuran $\mathrm{pH}$ bertujuan untuk mengetahui waktu jenuh resin sehingga dapat menentukan waktu proses pertukaran kation dihentikan. Waktu jenuh resin dapat ditunjukkan dari jumlah fraksi efluen yang dihasilkan. Semakin sedikit jumlah fraksi efluen, maka semakin cepat pula resin penukar kation menjadi jenuh.

Banyaknya ion $\mathrm{H}^{+}$yang ada dalam tiap fraksi efluen dapat dinyatakan dengan meq ion $\mathrm{H}^{+}$. Semakin besar nilai meq ion $\mathrm{H}^{+}$, maka semakin banyak pula ion $\mathrm{H}^{+}$yang dilepaskan oleh resin ke dalam efluen. Dengan kata lain, semakin banyak pula ion $\mathrm{Na}^{+}$dalam limbah air terproduksi yang dapat dipertukarkan dengan ion $\mathrm{H}^{+}$dari resin [12] 
Senyawa uranium dalam $\mathrm{pH}$ rendah akan mengalami proses ionisasi sehingga memudahkan proses pertukaran ion dengan resin penukar ion seperti terlihat pada reaksi di bawah ini [13]:

$$
\begin{aligned}
& \mathrm{UO}_{2}\left(\mathrm{NO}_{3}\right)_{2} \longrightarrow \mathrm{UO}_{2}^{2+}+2 \mathrm{NO}^{3-} \\
& 2 \mathrm{H}^{+}+2 \mathrm{R}^{-}+\mathrm{UO}_{2}^{2+}+2 \mathrm{NO}^{3-} \\
& \stackrel{\mathrm{UO}_{2} \mathrm{R}_{2}+2 \mathrm{HNO}_{3}}{\longleftrightarrow}
\end{aligned}
$$

Proses pertukaran kation paling cepat terjadi untuk kondisi larutan limbah air terproduksi $\mathrm{pH}=7$. Pada kondisi larutan basa, kesetimbangan reaksi akan bergeser ke arah kanan, sehingga ion kompleks uranium yang dapat dipertukarkan oleh resin semakin banyak. Sebaliknya untuk kondisi larutan asam, kesetimbangan pertukaran kation akan bergeser ke arah kiri sehingga proses pengikatan kation kompleks uranium dalam larutan limbah cair terproduksi menjadi terhambat. Selain itu, semakin besar bobot resin yang digunakan, maka semakin rendah $\mathrm{pH}$ yang dihasilkan [13].

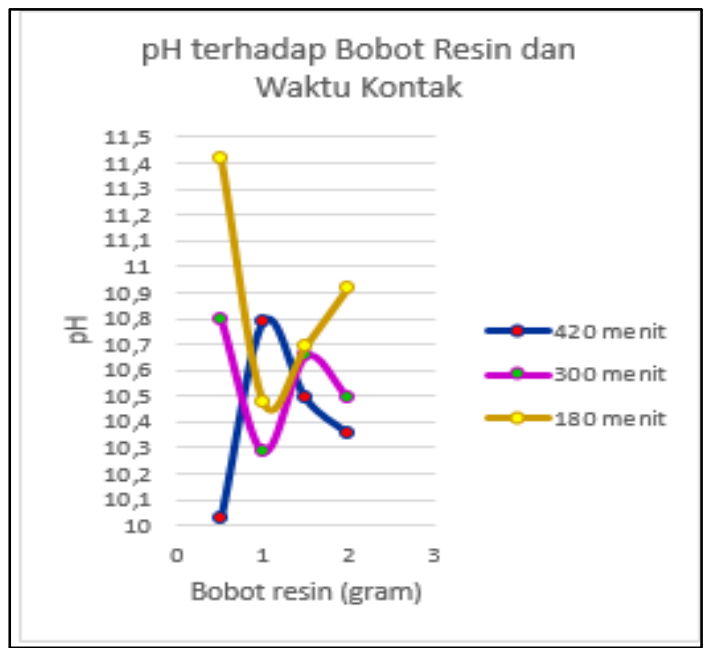

Gambar 2. Hasil analisis uranium dalam pengukuran $\mathrm{pH}$ terhadap bobot resin.

Gambar 2 menunjukkan bahwa $\mathrm{pH}$ berpengaruh terhadap penurunan kandungan uranium. Terlihat bahwa $\mathrm{pH}$ yang dihasilkan berfluktuasi dengan waktu, pada kontak yang berbeda. Namun, $\mathrm{pH}$ hasil proses mengalami penurunan. Hal ini membuktikan bahwa memang kesetimbangan pada reaksi bergeser ke kanan, sehingga ion kompleks uranium yang dipertukarkan oleh resin semakin banyak. Namun, dalam prosesnya memang belum maksimal karena dapat terhambat oleh faktor pengadukan yang tidak sama antara satu sampel dengan lainnya. Besaran $\mathrm{pH}$ akan berbanding terbalik dengan nilai TDS dan konduktivitas karena $\mathrm{pH}$ hanya memperhatikan kejenuhan efluen dari hasil proses pertukaran ion.

\section{Pengaruh nilai TDS (Total Dissolved Solid) dan Konduktivitas pada Proses Pertukaran Ion}

Nilai TDS merupakan jumlah padatan terlarut yang ada dalam larutan (dalam hal ini adalah limbah cair). Nilai TDS dapat diukur dan nilainya akan berbanding lurus dengan konduktivitas.

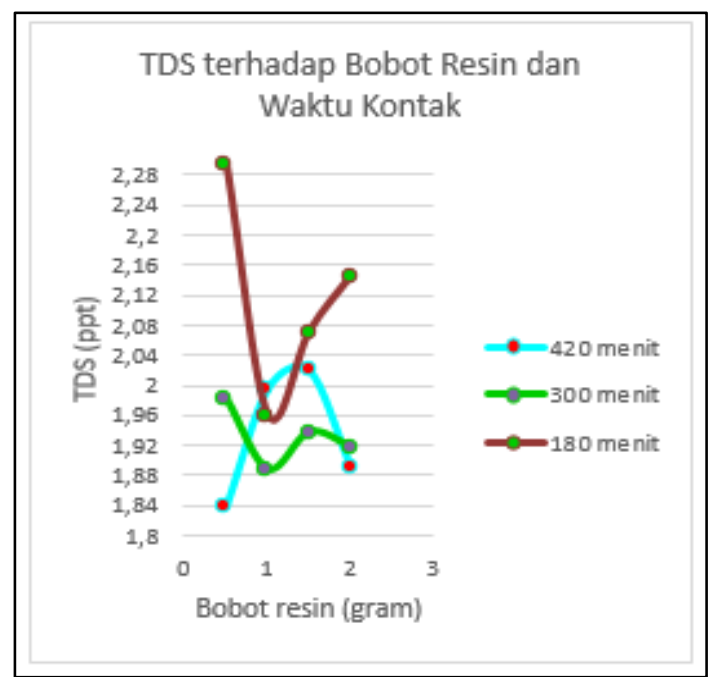

Gambar 3. Nilai konduktivitas terhadap bobot resin dan waktu kontak.

Berdasarkan hasil yang diperoleh, semakin besar bobot resin yang digunakan, maka penurunan TDS akan semakin tinggi. 
Hal ini dikarenakan pada tahap adsorpsi, semua pengotor yang tidak diinginkan yaitu TDS akan berkurang konsentrasinya. Limbah cair monasit memiliki kandungan ion-ion uranium $\left(\mathrm{U}^{2+}\right)$. Ketika limbah air terproduksi yang mengandung ion $\mathrm{U}^{2+}$ dan melakukan kontak dengan resin penukar kation yang mengandung ion $\left(\mathrm{Na}^{+}\right)$, maka ion $\mathrm{Na}^{+}$akan meninggalkan resin dan masuk ke dalam larutan sebagai efluen, sedangkan ion $\mathrm{U}^{2+}$ akan teradsorpsi di permukaan resin akan menggantikan ion $\mathrm{Na}^{+}$dari resin [14]. Pertukaran dengan menggunakan resin penukar kation hanya dapat menurunkan konsentrasi ion positif yang ada dalam limbah cair monasit tanpa memengaruhi konsentrasi ion negatif yang terdapat dalam limbah cair monasit.

Konduktivitas merupakan ukuran kemampuan suatu larutan untuk menghantarkan arus listrik. Arus listrik di dalam larutan dihantarkan oleh ion yang terkandung di dalamnya. Ion memiliki karakteristik tersendiri yang bisa menghantarkan arus listrik, sehingga nilai konduktivitas listrik hanya menunjukkan konsentrasi ion total dalam larutan [15].

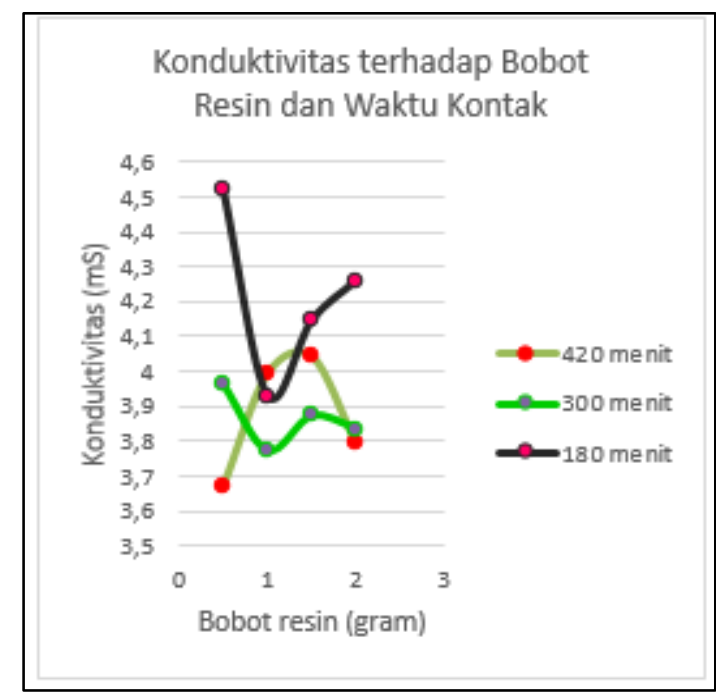

Gambar 4. Nilai konduktivitas terhadap bobot resin dan waktu kontak.
Dalam hal ini, nilai konduktivitas hasil proses pertukaran ion fluktuatif, namun jika dibandingkan hasilnya, persentase penurunan kandungan uranium yang optimal, yaitu pada waktu kontak 300 menit dengan bobot resin 1,5 gram sebesar $3,873 \mathrm{~S} / \mathrm{m}$, menunjukan bahwa ion positif yang ada pada limbah cair menurun. Dapat disimpulkan bahwa padatan terlarut dalam hal ini adalah ion kompleks uranium berkurang karena penyerapan oleh resin Tulsion T-40 Na.

Dari gambar tersebut juga dapat dilihat bahwa pola dari nilai TDS dan konduktivitas sama, sehingga nilai TDS dan konduktivitas hasil pertukaran ion menggunakan resin Tulsion T-40 Na berbanding lurus.

Hasil dari penelitian ini menunjukkan bahwa resin kation Tulsion T-40 Na memiliki penyerapan maksimal dan konsentrasi penurunan yang optimal pada waktu kontak yang tidak lebih dari 180 menit dan bobot resin yang sesuai perbandingannya dengan kapasitas limbah cair yang digunakan. Jika dibandingkan dengan hasil penelitian sebelumnya [10], pertukaran ion menggunakan resin kation terbukti lebih efektif dibandingkan dengan anion karena uranium berada pada muatan positif.

Penurunan konsentrasi uranium terlihat jelas dari kondisi awal dan akhir pada perhitungan efesiensi konsentrasi uranium. Penggunaan metode ini, hasilnya lebih efektif dibandingkan dengan tidak menggunakan pertukaran ion. Namun, untuk perbaikan ke depannya bobot resin bisa lebih ditambahkan variasinya dalam jumlah yang besar agar perbandingan dalam penggunaannya terlihat.

\section{KESIMPULAN}

Proses pertukaran ion dilakukan pada limbah cair dari pengolahan monasit yang dihasilkan di PTBGN-BATAN. Penelitian menggunakan resin Tulsion T-40 Na dengan 
variasi bobot resin dan waktu kontak menunjukkan adanya penurunan kandungan uranium. Hasil penelitian menunjukan bahwa kondisi optimal terdapat pada bobot resin sebesar 1,5 gram dengan waktu kontak selama 300 menit menghasilkan penurunan kandungan uranium sebesar $83,40 \%$.

\section{UCAPAN TERIMA KASIH}

Ucapan terima kasih kami sampaikan kepada Pusat Teknologi Bahan Galian Nuklir-BATAN yang telah menyediakan tempat penelitian serta bahan dan peralatan yang dibutuhkan dalam penelitian.

\section{DAFTAR PUSTAKA}

[1] G. B. Abaka-Wood, J. Addai-Mensah, and W. Skinner, "Magnetic Separation of Monazite from Mixed Minerals," in Chemeca Conference, 2016.

[2] M. Anggraini, Sumarni, Sumiarti, Rusyidi, and S. Waluyo, "Pengendapan Unsur Tanah Jarang Hasil Digesti Monasit Bangka Menggunakan Asam Sulfat," Eksplorium, vol. 33, no. 2, pp. 121-128, 2012.

[3] H. L. Nuri, F. Riza, S. Waluyo, B. Sarono, Arif, and Susilaningtyas, "Pengolahan Monasit dari Limbah Penambangan Timah: Pemisahan Logam Tanah Jarang (RE) dari U dan Th," in Prosiding Presentasi Ilmiah Daur Bahan Bakar Nuklir V P2TBDU dan P2BGN-BATAN, 2000, pp. 54-60.

[4] E. Rifandriyah, R. Pudjianto, Zahardi, and Susilaningtyas, "Pengolahan Bijih Uranium Asal Rirang: Pemisahan LTJ dari Hasil Digesti Basa," in Prosiding Presentasi Ilmiah Daur Bahan Bakar Nuklir V P2TBDU dan P2BGN-BATAN, 2000, pp. 94-101.
[5] I. Gaballah, E. Allain, M.-C. Meyer-Joly, and K. Malau, "A possible Methode for the Characterization of Amophous Slags: Recovery of Refractory Metal Oxide from Tin Slags," Metall. Mater. Trans. B, vol. 23, no. 3, pp. 249259, 1992.

[6] BAPETEN, Peraturan Kepala Badan Pengawas Tenaga Nuklir Nomor 16 Tentang Tingkat Klierens Tahun 2012. Jakarta, 2012.

[7] E. Hiswara, Buku Pintar Proteksi dan Keselamatan Radiasi di Rumah Sakit. Jakarta: BATAN Press, 2015.

[8] C. A. Finch, Ion Exchangers. Berlin \& New York: Wiley, 1993.

[9] Lenntech, Specification Product Brosur: Tulsion T-40. Delfgauw: Thermax-Lenntech, 2008.

[10] Supardi and B. Masduki, "Pengolahan Limbah Radioaktif Uranium Cair dengan Resin Penukar Ion Campuran," in Prosiding Presentasi Jlmiah Daur Bahan Bakar Nuklir PEBN-BATAN, 1996, pp. 308-312.

[11] Kementerian Lingkungan Hidup, Peraturan Menteri Lingkungan Hidup RI No 5 Tahun 2014 tentang Baku Mutu Air Limbah. Jakarta, 2014.

[12] T. Partuti, "Efektivitas Resin Penukar Kation untuk Menurunkan Kadar Total Dissolved Solid (TDS) dalam Limbah Air Terproduksi Insutri MIGAS," J. Integr. Proses, vol. 5, no. 1, pp. 1-7, 2014.

[13] F. DeSilva, Uranium Removal by Ion Exchange: Measures to Reduce Uranium in the Drinking Water Supply. West Berlin, 2005.

[14] E. Rosenberg, G. Pinson, and R. Tsosie, "Uranium Remediation by Ion Exchange and Sorption Methods: A Critical Review," Johnson Matthey Technol. Rev., vol. 60, no. 1, pp. 59-77, 2016.

[15] F. Irwan and Afdal, "Analisis Hubungan Konduktivitas Listrik dengan Total Dissolved Solid (TDS) dan Temperatur pada Beberapa Jenis Air," J. Fis. Unand, vol. 5, no. 1, pp. 85-93, 2016. 